\title{
Optimization of sensitivity and noise in piezoresistive cantilevers
}

\author{
Yu, Xiaomei; Thaysen, Jacob; Hansen, Ole; Boisen, Anja
}

Published in:

Journal of Applied Physics

Link to article, DOI:

$10.1063 / 1.1493660$

Publication date:

2002

Document Version

Publisher's PDF, also known as Version of record

Link back to DTU Orbit

Citation (APA):

Yu, X., Thaysen, J., Hansen, O., \& Boisen, A. (2002). Optimization of sensitivity and noise in piezoresistive cantilevers. Journal of Applied Physics, 92(10), 6296-6301. https://doi.org/10.1063/1.1493660

\section{General rights}

Copyright and moral rights for the publications made accessible in the public portal are retained by the authors and/or other copyright owners and it is a condition of accessing publications that users recognise and abide by the legal requirements associated with these rights.

- Users may download and print one copy of any publication from the public portal for the purpose of private study or research.

- You may not further distribute the material or use it for any profit-making activity or commercial gain

- You may freely distribute the URL identifying the publication in the public portal

If you believe that this document breaches copyright please contact us providing details, and we will remove access to the work immediately and investigate your claim 


\title{
Optimization of sensitivity and noise in piezoresistive cantilevers
}

\author{
Xiaomei Yu \\ Mikroelektronik Centret, Bldg. 345E, Technical University of Denmark, DK-2800, Lyngby, Denmark \\ and Institute of Microelectronics, Peking University, Beijing, 100871, China \\ J. Thaysen, ${ }^{\text {a) }}$ O. Hansen, and A. Boisen ${ }^{\text {a) }}$ \\ Mikroelektronik Centret, Bldg. 345E, Technical University of Denmark, DK-2800, Lyngby, Denmark
}

(Received 30 October 2001; accepted for publication 23 May 2002)

\begin{abstract}
In this article, the sensitivity and the noise of piezoresistive cantilevers were systematically investigated with respect to the piezoresistor geometry, the piezoresistive materials, the doping dose, the annealing temperature, and the operating biased voltage. With the noise optimization results, dimension optimized array cantilevers were designed and fabricated by using single-crystal silicon, low-pressure chemical-vapor deposition (LPCVD) amorphous silicon and microcrystalline silicon as piezoresistive layers. Measurement results have shown that the smallest Hooge factor $(\alpha)$ was $3.2 \times 10^{-6}$, the biggest gauge factors was 95 , and the minimum detectable deflection (MDD) at $6 \mathrm{~V}$ and $200 \mathrm{~Hz}$-measurement bandwidth was $0.3 \mathrm{~nm}$ for a single-crystal silicon cantilever. Of the two LPCVD silicon piezoresistive cantilevers, amorphous silicon piezoresistors had relatively lower $1 / f$ noise. The MDD for a LPCVD silicon cantilever at a $200 \mathrm{~Hz}$-measurement bandwidth was $0.4 \mathrm{~nm}$. For all kinds of piezoresistive cantilevers, the $1 / f$ noises were decreased by $35 \%-50 \%$ and the gauge factors were decreased by $60-70 \%$ if the doping dose were increased by ten times. The annealing at $1050{ }^{\circ} \mathrm{C}$ for $30 \mathrm{~min}$ decreased $1 / f$ noise by about $65 \%$ compared with the $950{ }^{\circ} \mathrm{C}$ for 10 min treatments. The cantilevers with a relatively higher-doping dose gave smaller MDD even though the gauge factors of them were decreased by nearly a factor of 1.8. The higher-biased voltages had no great improvements on the MDD due to the $1 / f$ noise dominance. (c) 2002 American Institute of Physics. [DOI: 10.1063/1.1493660]
\end{abstract}

\section{INTRODUCTION}

With the invention of the scanning tunneling microscope in $1981^{1}$ and the development of the first atomic force microscope (AFM) in 1986, ${ }^{2}$ various cantilever-based sensors receive more and more attention for their small volume and high sensitivity. The cantilever deflection can be precisely measured by optical or electrical techniques. Optical methods have been developed for detecting cantilever deflection based on light beam reflection or laser light interferometry, which can detect cantilever deflection in the subangstrom regime. However, the precise aligning of laser and a large fraction of the size limit their applications at different environments. An attempt to get rid of these problems is to integrate the cantilever with capacitive, piezoelectric, or piezoresistive devices into its construction. The piezoresistive cantilever approach was first proposed by Tortonese et al. and successfully used in AFM. ${ }^{3}$ Since the initial development, different piezoresistive cantilevers have been realized by a few groups. ${ }^{4-6}$

An important parameter in the cantilever-based sensor is the minimum detectable deflection (MDD). For a cantilever with piezoresistive readout, the MDD depends not only on its deflection sensitivity, but is mainly limited by the noise level of the piezoresistor. Although miniaturized sensors

\footnotetext{
a) Also at: Cantion A/S, Orsteds Plads, Bldg 347, DK-2800, Lyngby, Denmark.
}

show higher sensitivity, there are noise problems, which will limit further increase of the resolution. The trade off between sensitivity and noise is key in fabricating a high-quality microsensor. Tortonese et al. indicated that, in their singlecrystalline silicon AFM, the integrated noise from $0.01 \mathrm{~Hz}$ to $1 \mathrm{kHz}$ was equivalent to a $1.35 \AA_{\text {rms }}$ at $5 \mathrm{~V}$ biased voltages. ${ }^{3}$ In 1996, Chui and Stowe reported that their cantilever integrated noise from 1 to $200 \mathrm{~Hz}$ was about $0.5 \AA$ with its corner frequency at about $200 \mathrm{~Hz} .{ }^{4}$ Gotszalk et al. gave a 0.7 $\AA$ MDD for their design at $0.5 \mathrm{~V}, 1000 \mathrm{~Hz}$ bandwidth. ${ }^{5} \mathrm{Har}-$ ley and Kenny in $2000,{ }^{6}$ had a summary on the piezoresistive cantilever design and processing connecting the noise and sensitivity, gave the Hooge factor $(\alpha)$ for single-crystal silicon was $3 \times 10^{-6}-3 \times 10^{-4}$. In the researches conducted by the above scientists, only single-crystal silicon was used as piezoresistive materials.

In this article, after successfully solving the noise measurement, systematical analysis on noise was done based on 192 Wheatstone bridges. Then, ten rectangular cantilevers with U-shaped piezoresistors had been designed in an array on two sides of a channel, which permits liquid to flow in it. Single-crystal silicon, microcrystalline silicon, and amorphous silicon had been used as piezoresistive materials since the last two materials are much cheaper and have wide applications in microelectronics industry. Two doping doses and two annealing conditions were selected in the processing. The calculated results of the Hooge factor $(\alpha)$, the gauge factor $(K)$, and the MDD of different cantilevers were given 


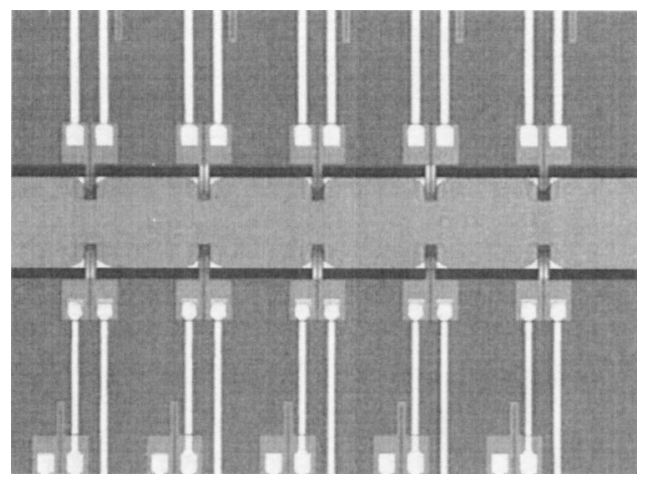

FIG. 1. SEM photgraph of a piezoresistive cantilevers. Ten cantilevers were designed on the two sides of a channel, and the cantilever size is $120 \mu \mathrm{m}$ $\times 38 \mu \mathrm{m}$.

and suggestions for improving resolution were put forward. These results will provide guidelines for the design and fabrication of low-noise cantilever-based sensors.

\section{THEORETICAL BACKGROUND}

Two types of noise we have to worry about in laboratory situations for a cantilever-based microsensor, intrinsic noises, and external noise. Four intrinsic noises in semiconductors are Johnson noise, shot noise, generation-recombination noise, and Hooge noise (1/f noise). Frequency-independent Johnson noise and low-frequency $1 / f$ noise are the two dominant noise sources affecting cantilever resolution. Johnson noise arises from the random motion of mobile carriers in resistive electrical materials at finite temperature $T$. The Johnson power noise spectral density $S_{V J}$ for a resistance $R$ is defined as

$$
S_{V J}=4 k_{B} T R,
$$

where $k_{B}$ is the Boltzmann constant.

A generally accepted empirical model to explain $1 / f$ noise in homogeneous materials was put forth in 1969 by Hooge. ${ }^{7}$ Thus, we analyze our experimental results according to Hooge's formular

$$
\frac{S_{V H}}{V^{2}}=\frac{\alpha}{f N},
$$

where $S_{V H}$ is the spectral power noise density corresponding voltage fluctuation, $V$ is the biased voltage across a resistor with a total number of carriers $N, f$ is frequency, and $\alpha$ is not a constant but a device dimension-independent parameter which is between $10^{-7}$ and $10^{-3} \cdot{ }^{9}\left(S_{V H} f\right)^{1 / 2}$ was used to indicate the $1 / f$ voltage noise power in our later discussions, which can be written as

$$
\left(S_{V H} f\right)^{1 / 2}=\left(\frac{\alpha}{p L W T}\right)^{1 / 2} V
$$

where $p$ is the carrier's concentration, $L, W$, and $T$ is the piezoresistor length, width, and thickness, respectively. The Hooge factors were then calculated with the linear relation between $S_{V H} f$ and surface area of piezoresistors. Unlike the Johnson noise source mentioned above, which is well understood, the origin of $1 / f$ noise is still an active research area.

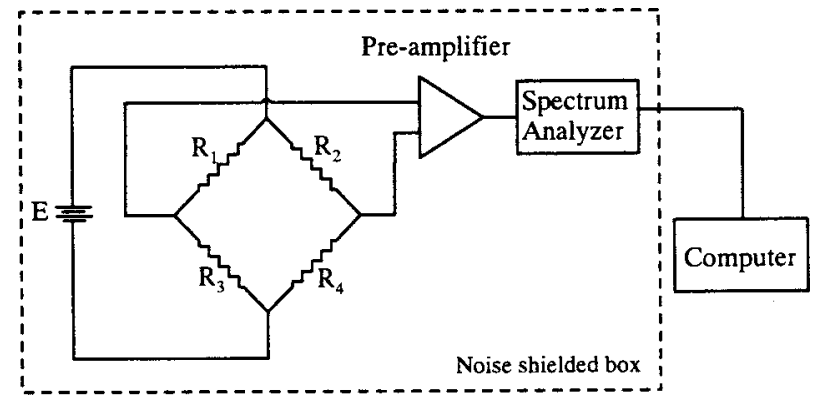

FIG. 2. Simplified diagram of noise measurement setup.

The $1 / f$ noise is a fluctuation in the conductivity. The measurements transform the existing conductivity fluctuation into voltage fluctuation. It is certain now that mobility fluctuations $(\Delta \mu)$ are the sources of $1 / f$ noise. Most authors have adequately interpreted the mobility fluctuation by the lattice scattering model. Whereas the impurity scatterings were considered to have no appreciable contributions to the $1 / f$ noise. ${ }^{8-14}$

When the cantilever is bent by a force $F$ acting on the end, and assuming that the cantilever is deflected only by the longitudinal stress and the cantilever resistor located at the maximum stress area, then the piezoresistive sensitivity, which is defined as a ratio of cantilever resistance change to the end deflection of the cantilever, is given by

$$
\frac{\Delta R}{R} / \Delta z=\frac{3 \pi E t(l-L / 2)}{2 l^{3}}=\frac{3 K t(l-L / 2)}{2 l^{3}},
$$

where $\Delta z$ is the vertical displacement of the cantilever end, $\pi$ is the longitudinal piezoresistive coefficient, $E$ is the Young modulus, $K=E \pi$ is the gauge factor, $l$ is the cantilever length, and $t$ the thickness.

If one of the four piezoresistors which make up of a Wheatstone bridge suffers the force $F$, there is the following relation between the resistance change $\Delta R$ and the output signal $V_{\text {out }}$ :

$$
\frac{\Delta R}{4 R}=\frac{V_{\text {out }}}{V_{\text {bias }}},
$$

where $V_{\text {bias }}$ is the biased voltage. The MDD of a cantilever depends on the minimum detectable signal which is determined by the noise level of the cantilever. The MDD $\left(z_{\min }\right)$ that corresponds to the total noise of the piezoresistors can finally be estimated by using formula (6) at a given measurement bandwidth $\left(f_{\max }-f_{\min }\right)$

$$
\begin{aligned}
z_{\min }= & \frac{4}{V_{\text {bias }}}\left[\frac{\alpha V^{2}}{N} \ln \frac{f_{\max }}{f_{\min }}+4 k_{B} T R\left(f_{\max }-f_{\min }\right)\right]^{1 / 2} / \\
& K \frac{3\left(l-\frac{1}{2} L\right) t}{2 l^{3}} .
\end{aligned}
$$

\section{EXPERIMENTS}

The array cantilevers will be used as biosensors at liquid environment. So the cantilevers were designed to work inside a small channel which was formed from front-side etching (Fig. 1). A full Wheatstone bridge was symmetrically 


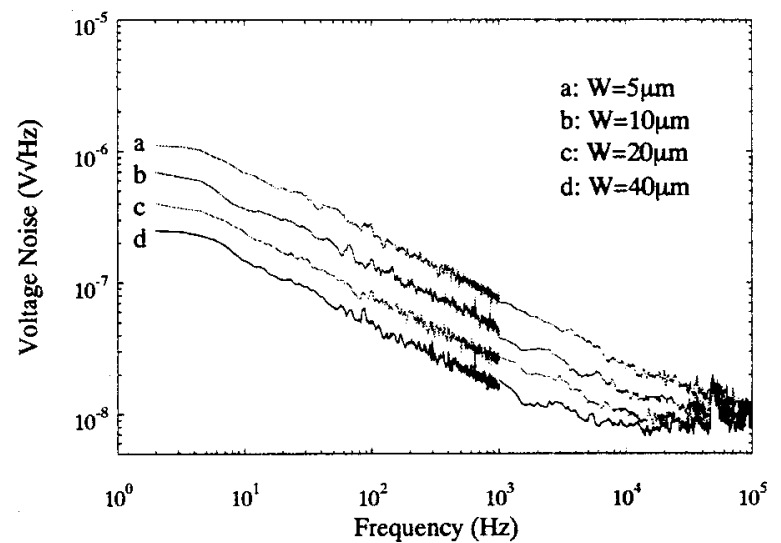

FIG. 3. Noise measurement spectra of a group of microcrystalline silicon samples. The piezoresistor dimension is $L / W=5$, the doping dose is 5 $\times 10^{15} \mathrm{~cm}^{-2}$, the annealing condition is $950{ }^{\circ} \mathrm{C}$ for $10 \mathrm{~min}$, and the biased voltage is $6 \mathrm{~V}$.

placed on chip, with two resistors on cantilevers and two resistors on the substrate. One cantilever can be used as the reference cantilever and the other can be used for the measurement. Geometry optimized cantilevers were designed in a rectangle based on the noise optimization results. The three dimensions are: $80 \mu \mathrm{m} \times 38 \mu \mathrm{m} ; 120 \mu \mathrm{m} \times 38 \mu \mathrm{m}$; and $120 \mu \mathrm{m} \times 56 \mu \mathrm{m}$. The materials used to fabricate our cantilevers are single-crystal silicon, amorphous silicon, and microcrystalline silicon.

The starting materials of the single-crystal silicon cantilevers is silicon-on-insulator wafers with a $220 \mathrm{~nm}$ silicon membrane after thinning down the top silicon layer, and a $400 \mathrm{~nm}$ silicon dioxide intermediate layer. Amorphous silicon $\left(580^{\circ} \mathrm{C}\right)$ and microcrystalline silicon $\left(610^{\circ} \mathrm{C}\right)$ cantilevers were fabricated from a $55 \mathrm{~nm}$ silicon nitride with lowpressure chemical-vapor deposition (LPCVD) on silicon wafers. Next, $150 \mathrm{~nm}$ amorphous silicon and microcrystalline silicon layers were LPCVD separately. Wafers were divided into two groups for boron-ion implantation at $30 \mathrm{keV}$ with the dose of $5 \times 10^{13} \mathrm{~cm}^{-2}$ or $5 \times 10^{14} \mathrm{~cm}^{-2}$ for singlecrystal silicon and $5 \times 10^{14} \mathrm{~cm}^{-2}$ or $5 \times 10^{15} \mathrm{~cm}^{-2}$ for amorphous and microcrystalline silicon layers. The piezoresistors were patterned and then defined using $\mathrm{SF}_{6}$ reactive ion etching. The contact pad and the cross beam of all wafers were $5 \times 10^{15} \mathrm{~cm}^{-2}$ boron ion implanted with the help of a mask in order to neglect the resistance of the cross beam and form good electrical contact with metal. Where after $280 \mathrm{~nm}$ silicon nitride was deposited as a protection layer and as an etch

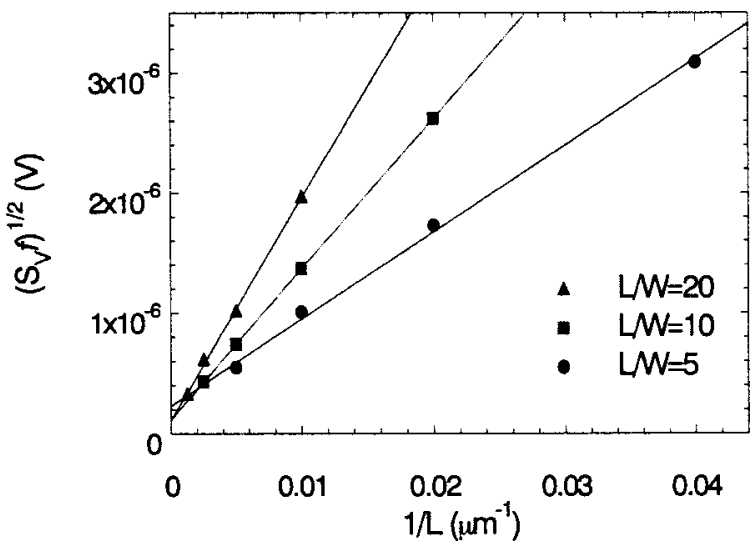

FIG. 4. Calculated relation of noise level versus $1 / L$ for a group of microcrystalline silicon samples. The doping dose is $5 \times 10^{15} \mathrm{~cm}^{-2}$, and annealed at $1050^{\circ} \mathrm{C}$ for $30 \mathrm{~min}$.

mask for the later wet etching. The doped boron was activated at $950^{\circ} \mathrm{C}$ for $10 \mathrm{~min}$ or $1050^{\circ} \mathrm{C}$ for $30 \mathrm{~min}$.

The cantilevers were defined from the front side. Silicon nitride were etched using RIE, and then the cantilevers were released by a $\mathrm{KOH}$ front-side etching. The channel thickness had been controlled to be about $50 \mu \mathrm{m}$. Contact holes were opened with the help of LPCVD $\mathrm{SiO}_{2}$. Finally, 20/500 nm Ti/Al metal wiring film for the piezoresistor was made by $e$-beam evaporation.

\section{RESULTS AND DISCUSSIONS}

\section{A. Noise in piezoresistors}

The noise measurements were performed at room temperature and in air by selecting the measurement bandwidth to be $2 \mathrm{~Hz}-1 \mathrm{kHz}$ and $1 \mathrm{kHz}-20 \mathrm{kHz}$. The output signals from the bridges were first amplified 100 or 1000 times with a low-noise preamplifier. A HP Spectrum Analyzer recorded the amplified signals at different dc-biased voltages. Figure 2 is the simplified diagram of the measurement setup. In order to distinguish intrinsic noise from external noise, the device was first shielded from measurement instruments, and then the device together with the instruments were again enclosed inside a noise-shielded box. After careful attention to shielding and designing, ideal noise spectra at different biased voltage were successfully recorded.

Figure 3 presents a group of typical noise spectra, which were measured from differently sized microcrystalline silicon piezoresistors. Similar noise spectra of geometrical de-

TABLE I. Calculated $\alpha$ values of different piezoresistive materials, which were averaged from differently sized piezoresistors.

\begin{tabular}{|c|c|c|c|c|c|c|}
\hline \multirow[b]{3}{*}{ Materials } & \multicolumn{3}{|c|}{ Annealing at $950^{\circ} \mathrm{C}$ for $10 \mathrm{~min}$} & \multicolumn{3}{|c|}{ Annealing at $1050{ }^{\circ} \mathrm{C}$ for $30 \mathrm{~min}$} \\
\hline & \multicolumn{3}{|c|}{ Doping dose $\left(\mathrm{cm}^{-2}\right)$} & \multicolumn{3}{|c|}{ Doping dose $\left(\mathrm{cm}^{-2}\right)$} \\
\hline & $5 \times 10^{13}$ & $5 \times 10^{14}$ & $5 \times 10^{15}$ & $5 \times 10^{13}$ & $5 \times 10^{14}$ & $5 \times 10^{15}$ \\
\hline Amorphous $\mathrm{Si}$ & ------ & $1.3 \times 10^{-3}$ & $1.3 \times 10^{-3}$ & ------ & $6.5 \times 10^{-4}$ & $8.0 \times 10^{-4}$ \\
\hline Microcrystalline $\mathrm{Si}$ & ------ & $1.8 \times 10^{-3}$ & $1.5 \times 10^{-3}$ & ----- & $9.9 \times 10^{-4}$ & $1.2 \times 10^{-3}$ \\
\hline Single-crystal Si & $5 \times 10^{-6}$ & $5.7 \times 10^{-6}$ & ----- & $3.2 \times 10^{-6}$ & $3.2 \times 10^{-6}$ & ------ \\
\hline
\end{tabular}




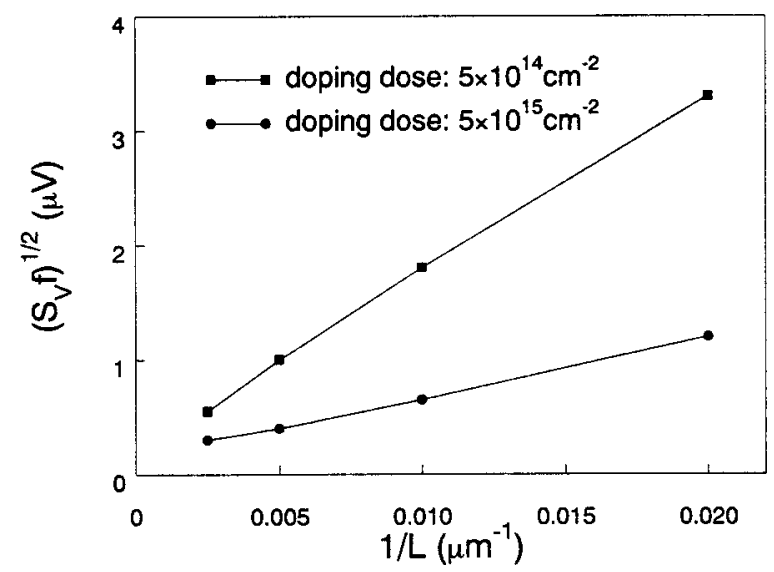

FIG. 5. Noise level comparison of two groups of amorphous silicon samples at two doping doses. The piezoresistor dimension is $L / W=10$, and annealed at $1050^{\circ} \mathrm{C}$ for $30 \mathrm{~min}$.

pendence as Fig. 3 were recorded for other kinds of piezoresistive materials. Several trends are clear now: $1 / f$ noises, given in Eq. (2), are the dominant noise source at low frequencies since the fitted line slope was -0.5 . The $1 / f$ noises decreased as the piezoresistor volume is increased. Beyond the corner frequency (the intersection frequency of Johnson noise and $1 / f$ noise), only Johnson noises were observed. The values of measured Johnson noise were in good agreement with theoretical Johnson noise level.

After fitting the measurement data, the $\left(S_{V} f\right)^{1 / 2}$ of every spectrum had been calculated reasonably. The relations between $\left(S_{V} f\right)^{1 / 2}$ and resistors geometry were then obtained. Figure 4 gives one of the graphs of $\left(S_{V f}\right)^{1 / 2}$ versus $1 / L$ which was obtained from differently sized microcrystalline silicon samples. The linear relation between $\left(S_{V f}\right)^{1 / 2}$ and $1 / L$ at constant $L / W$ is also in good agreement with the theory, which was expected in Eq. (3). The $\alpha$ values were calculated with the fitted line slope, which are summarized in Table I for all piezoresistive materials.

Comparing the noise measurement results of three piezoresistive materials, it was found that the $1 / f$ noise of single-crystal silicon samples is about $1 / 10$ as that of LPCVD silicon samples. The calculated $\alpha$ of single-crystal silicon given in Table I are 2-3 orders lower than that of LPCVD silicon piezoresistors, which are between 3.2 $\times 10^{-6}$ and $5.7 \times 10^{-6}$. Compared with the results summarized by Harley and Kenny for different single-crystal silicon cantilever, ${ }^{5}$ the $\alpha$ values of our single-crystal silicon cantilever are lower. Of the two LPCVD piezoresistive materials, amorphous silicon has relatively lower noise level and $\alpha$ values. The $\alpha$ of LPCVD silicon piezoresistors are between $6.5 \times 10^{-4}$ and $1.8 \times 10^{-3}$. The higher $1 / f$ noises in LPCVD silicon piezoresistive materials were believed to originate from the lattice scattering. The magnitude of the $1 / f$ noise depends on the contact areas between the grains. Small contact areas between the grains produce stronger $1 / f$ noise. ${ }^{10}$

The noise level comparisons of different doping concentration had been made for all materials with the other process parameters being totally identical. Figure 5 is the noise measurement results of two groups of amorphous silicon samples. All the measurement results indicated that the $1 / f$

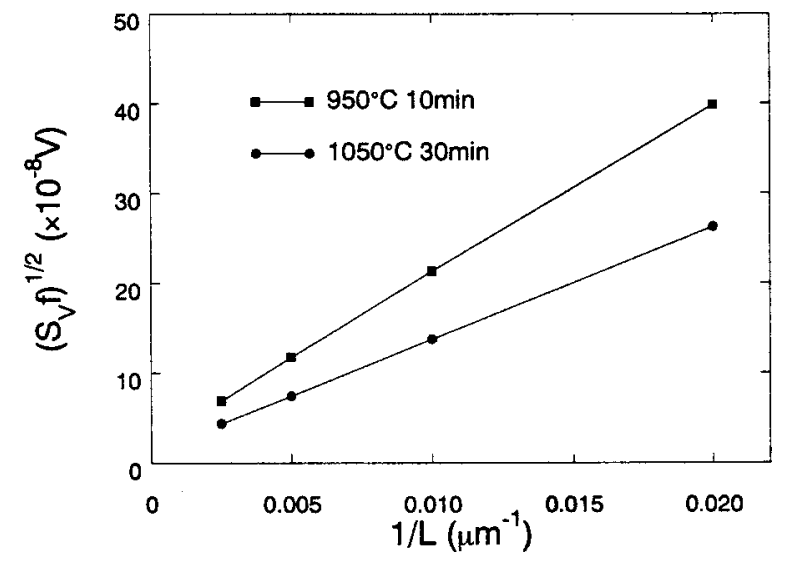

FIG. 6. Noise level comparison of two groups of amorphous silicon samples at two annealing conditions. The piezoresistor dimension is $L / W=5$, and the doping dose is $5 \times 10^{15} \mathrm{~cm}^{-2}$.

noises were decreased by $35 \%-50 \%$ if increasing the doping dose ten times. The value of $35 \%-50 \%$ is higher than $1 / \sqrt{ } 10$ which is expected in Eq. (2). We can see from Table I, that the calculated $\alpha$ have almost no relation with the doping dose although the $1 / f$ noises have big differences at this time. This result verifies that $1 / f$ noise arises from lattice scattering, but not from impurity scattering.

Two different annealing conditions, $950^{\circ} \mathrm{C}$ for $10 \mathrm{~min}$ or $1050^{\circ} \mathrm{C}$ for $30 \mathrm{~min}$ had been tested in this research. It was found that the $1 / f$ noise and a values of $1050^{\circ} \mathrm{C} 30 \mathrm{~min}$ annealing samples were reduced by about $65 \%$ compared with that of the $950^{\circ} \mathrm{C} 10 \mathrm{~min}$ annealing samples. One of the comparison results for two amorphous silicon resistors is plotted in Fig. 6. Similar trends of $1 / f$ noise differences were observed for other samples.

\section{B. Operation}

After optimized cantilever had been fabricated, the final question is what biased voltage for operation should be selected. According to Eq. (5), it seems that the sensitivity improves linearly with the biased voltage. Actually, at the $1 / f$ noise dominant range, the noise voltage varies as $V_{\text {bias }}$ at the

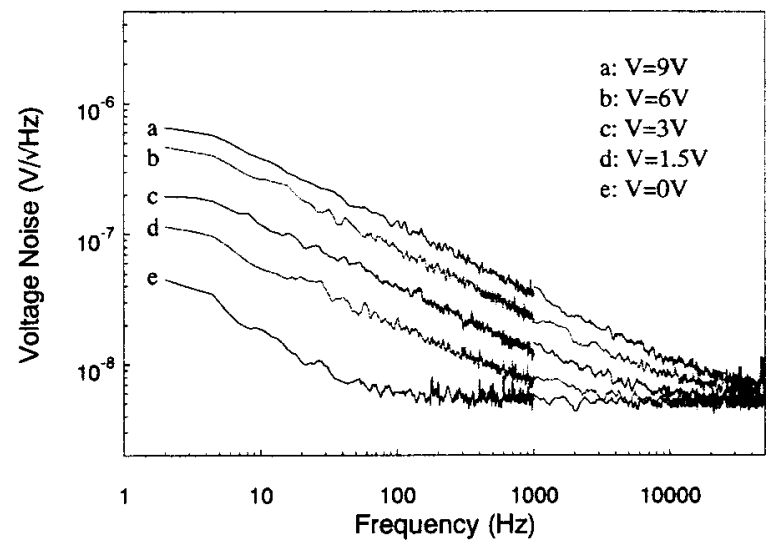

FIG. 7. Noise measurement spectra of an amorphous silicon sample at different biased voltages. The piezoresistor dimension is $L / W=5, L$ $=100 \mu \mathrm{m}$, the doping dose is $5 \times 10^{15} \mathrm{~cm}^{-2}$, and annealed at $950{ }^{\circ} \mathrm{C}$ for 10 $\min$. 


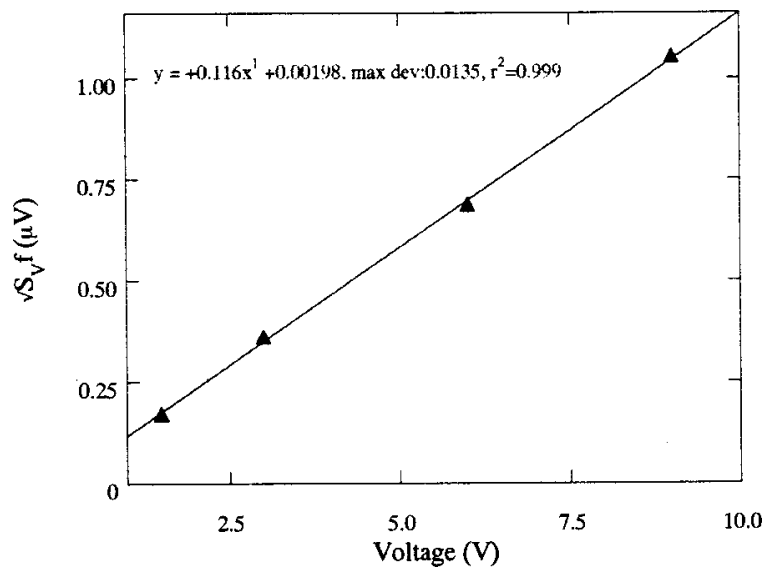

FIG. 8. Noise level vs bias voltages, which was calculated from the results of Fig. 7.

same time. After increasing the biased voltage, the $1 / f$ noise will limit sensitivity at the same order. So there should be no preference for a particular biased voltage at low frequency.

Figure 7 depicts one of the noises spectra at different dc-biased voltages, which was obtained from an amorphous silicon sample. The relation of $\left(S_{V} f\right)^{1 / 2}$ versus biased voltages is shown in Fig. 8. It is obvious that the $1 / f$ noises increase linearly with the increasing of the biased voltage, which is in fairly good agreement with the theory.

\section{Cantilever sensitivities}

The cantilever sensitivities were obtained by measuring the resistance change as a function of the cantilevers bending. One of the measurement relations between relative resistance change $(\Delta R / R)$ and vertical deflection $(\Delta z)$ is shown in Fig. 9. The slopes of the curves give the deflection sensitivities. For the cantilevers with single-crystal silicon integrated resistors, the sensitivities were calculated to be $2.0 \times 10^{-7} \AA^{-1}-3.5 \times 10^{-7} \AA^{-1}$. The deflection sensitivities of the cantilevers with integrated amorphous silicon and microcrystalline silicon resistors were $0.5 \times 10^{-7} \AA^{-1}-0.9$ $\times 10^{-7} \AA^{-1}$. Table II lists all the calculated results of gauge factors, which were calculated from Eq. (4) by considering the mechanical differences of different layers. As expected, single-crystal silicon cantilevers showed higher $K$ than LPCVD silicon cantilevers, which are 50-95. The $K$ corresponding LPCVD silicon cantilevers are between 17 and 36. The gauge factors were decreased by about $60 \%$ if the dop-

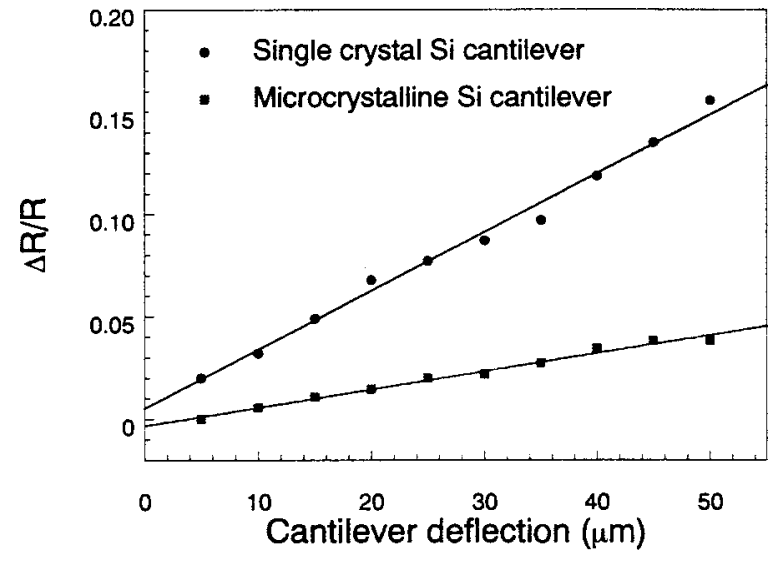

FIG. 9. Comparison of relative resistance change vs cantilever deflection for a single-crystal silicon and a microcrystalline silicon cantilevers.

ing level were increased by ten times for most cantilevers. The two different annealing procedures had no obvious effect on the gauge factors.

\section{Cantilever resolutions}

The calculations of MDD (Table III) were carried out at two measurement bandwidths $(1 \mathrm{~Hz}-200 \mathrm{~Hz}$ or $1 \mathrm{~Hz}-1000$ $\mathrm{Hz}$ ) by substituting the $\alpha$ of Table I, $K$ of Table II, and cantilever geometry into Eq. (6). During the calculations, the biased voltage was $6 \mathrm{~V}$; the geometries were selected to be $120 \mu \mathrm{m} \times 56 \mu \mathrm{m} \times 0.9 \mu \mathrm{m}$ for single-crystal silicon cantilevers and $120 \mu \mathrm{m} \times 56 \mu \mathrm{m} \times 0.5 \mu \mathrm{m}$ for LPCVD silicon cantilevers. We can see from Table III that the MDD of our single-crystal silicon cantilevers is only $0.03 \mathrm{~nm}$ at a $200 \mathrm{~Hz}$ bandwidth and $0.06 \mathrm{~nm}$ at a $1000 \mathrm{~Hz}$ bandwidth. For LPCVD silicon cantilevers, the MDD is $0.4-1.2 \mathrm{~nm}$ at a 200 $\mathrm{Hz}$ bandwidth and $0.5-1.5 \mathrm{~nm}$ at a $1000 \mathrm{~Hz}$ bandwidth. The MDD of single-crystal silicon cantilever are about a factor of ten smaller than that of LPCVD silicon cantilever at both bandwidths when the other process parameters were identical. Surprisingly, the cantilevers with higher doping gave relatively smaller MDD even though the $K$ were decreased by nearly a factor of 1.8 at this time. This is obviously due to the lower-noise level at higher-doping concentration. $1050{ }^{\circ} \mathrm{C}$ for 30 min annealing decreased the MDD by a factor of 1.3 compared with $950{ }^{\circ} \mathrm{C}$ for 10 min annealing. Our results imply that atomic resolution should be obtainable with both single-crystal silicon and LPCVD silicon cantilevers.

TABLE II. Calculated gauge factors of different cantilevers, which were averaged from three differently sized cantilevers.

\begin{tabular}{|c|c|c|c|c|c|c|}
\hline \multirow[b]{3}{*}{ Materials } & \multicolumn{3}{|c|}{ Annealing at $950^{\circ} \mathrm{C}$ for $10 \mathrm{~min}$} & \multicolumn{3}{|c|}{ Annealing at $1050^{\circ} \mathrm{C}$ for $30 \mathrm{~min}$} \\
\hline & \multicolumn{3}{|c|}{ Doping doses $\left(\mathrm{cm}^{-2}\right)$} & \multicolumn{3}{|c|}{ Doping doses $\left(\mathrm{cm}^{-2}\right)$} \\
\hline & $5 \times 10^{13}$ & $5 \times 10^{14}$ & $5 \times 10^{15}$ & $5 \times 10^{13}$ & $5 \times 10^{14}$ & $5 \times 10^{15}$ \\
\hline Amorphous Si & ----- & 31 & 22 & ----- & 32 & 19 \\
\hline Microcrystalline Si & ----- & 35 & 22 & ------ & 36 & 27 \\
\hline Single-crystal Si & 90 & 50 & ------ & 95 & 55 & ------ \\
\hline
\end{tabular}


TABLE III. Calculated MDD (nm) of different cantilevers at $200 \mathrm{~Hz}$ bandwidth, the number in parentheses is the MDD (nm) calculated at $1000 \mathrm{~Hz}$ bandwidth.

\begin{tabular}{|c|c|c|c|c|c|c|}
\hline \multirow[b]{3}{*}{ Materials } & \multicolumn{3}{|c|}{ Annealing at $950{ }^{\circ} \mathrm{C}$ for $10 \mathrm{~min}$} & \multicolumn{3}{|c|}{ Annealing at $1050^{\circ} \mathrm{C}$ for $30 \mathrm{~min}$} \\
\hline & \multicolumn{3}{|c|}{ Doping doses $\left(\mathrm{cm}^{-2}\right)$} & \multicolumn{3}{|c|}{ Doping doses $\left(\mathrm{cm}^{-2}\right)$} \\
\hline & $5 \times 10^{13}$ & $5 \times 10^{14}$ & $5 \times 10^{15}$ & $5 \times 10^{13}$ & $5 \times 10^{14}$ & $5 \times 10^{15}$ \\
\hline Amorphous $\mathrm{Si}$ & ----- & $1.1(1.3)$ & $0.5(0.6)$ & ------ & $0.7(0.9)$ & $0.4(0.5)$ \\
\hline Microcrystalline Si & ----- & $1.2(1.5)$ & $0.5(0.6)$ & ----- & $0.8(1.0)$ & $0.4(0.5)$ \\
\hline Single-crystal Si & $0.05(0.09)$ & $0.04(0.07)$ & ------ & $0.05(0.09)$ & $0.03(0.06)$ & ------ \\
\hline
\end{tabular}

The MDD rely not only on the mechanical properties of different materials, the geometry of piezoresistors, the measurement bandwidth and the piezoresistive characteristics of the cantilevers, but also on the operation voltages. A relation of the MDD versus biased voltages for single-crystal silicon cantilevers at two bandwidths is plotted in Fig. 10. The MDD decrease quickly as the biased voltage increase, and they get almost independent on the biased voltage when the voltages are higher than $3 \mathrm{~V}$. The threshold voltages are only about 1 $\mathrm{V}$ for LPCVD silicon cantilevers.

\section{CONCLUSIONS}

We have analyzed the noise, the sensitivity, and the MDD of piezoresistive cantilevers with respect to the piezoresistors geometry, the piezoresistive materials, the doping level, and the annealing temperature. The conclusions are as follows:

- $1 / f$ noise is the dominant noise source at low frequencies, which decreases linearly as the piezoresistor surface area increases and biased voltage decreases. At high frequencies, Johnson noise is the dominant. The measured Johnson noise is in good agreement with theoretical value.

- The calculated $\alpha$ of single-crystal silicon piezoresistors were $2-3$ orders lower than that of LPCVD silicon piezoresistors, which were $3.2 \times 10^{-6}-5.7 \times 10^{-6}$. Of the two

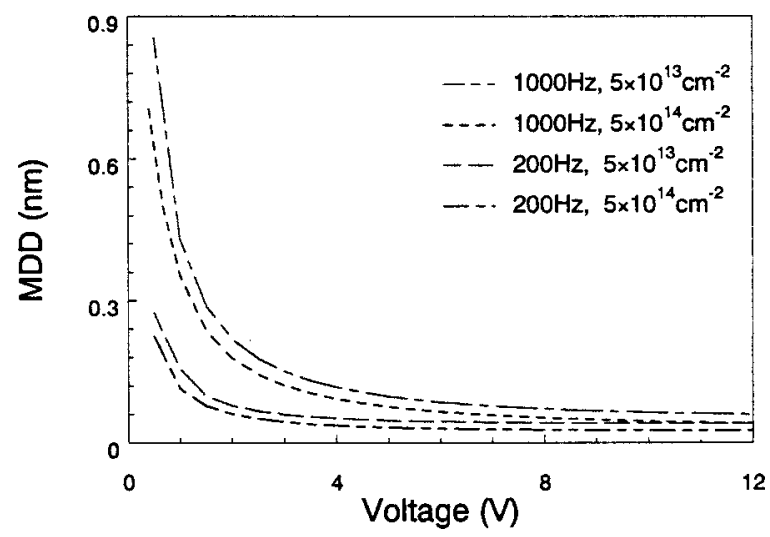

FIG. 10. Calculated MDD as a function of biased voltages for a singlecrystal silicon cantilever at two bandwidths and two doping doses. The cantilever dimension is $120 \mu \mathrm{m} \times 56 \mu \mathrm{m} \times 0.9 \mu \mathrm{m}$.
LPCVD silicon piezoresistors, amorphous silicon piezoresistors have relatively lower $1 / f$ noise and $\alpha$ values. The $K$ were calculated to be 50-95 for single-crystal silicon cantilevers and 19-36 for LPCVD silicon cantilever.

- The $1 / f$ noises were decreased by $35 \%-50 \%$ and the guage factors were decreased by about $60 \%$ if the doping dose were increased by ten times for all kinds of cantilevers. The $\alpha$ values were kept unaffected by the different doping doses.

- Compared with the $950{ }^{\circ} \mathrm{C}$ for 10 min treatment, the $1050^{\circ} \mathrm{C} 30$ min annealing decreased both $1 / f$ noises and $\alpha$ values by about $65 \%$.

- At a $200 \mathrm{~Hz}$ measurement bandwidth, The MDD of $0.03 \mathrm{~nm}$ for single-crystal silicon cantilevers and $0.4 \mathrm{~nm}$ for LPCVD silicon cantilevers have been achieved. The cantilevers with higher-doping dose gave relatively smaller MDD.

Optimum design and the process involved in a trade off of noise and sensitivity were obtained. We recommend $L / W=5$ or 10 with $L$ between 80 and $200 \mu \mathrm{m}$ to be the ideal piezoresistor size, $5 \times 10^{14} \mathrm{~cm}^{-2}$ for single-crystal silicon piezoresistors and $5 \times 10^{15} \mathrm{~cm}^{-2}$ for LPCVD silicon piezoresistors as the optimal doping dose, and $1050{ }^{\circ} \mathrm{C}$ for $30 \mathrm{~min}$ annealing as the better treatment condition. After the optimization, the $1 / f$ noises of our cantilevers had been decreased by more than ten times and the MDD had been decreased by a factor of three for the same piezoresistive materials. Both the single-crystal silicon cantilevers and the LPCVD silicon cantilevers can be used as piezoresistive biosensors for nanoscale detections.

${ }^{1}$ G. Binnig and H. Rohrer, Helv. Phys. Acta 55, 726 (1982).

${ }^{2}$ G. Binnig, C. F. Quate, and Ch. Gerber, Phys. Rev. Lett. 56, 930 (1986).

${ }^{3}$ M. Tortonese, H. Yamada, R. C. Barett, and C. F. Quate, IEEE 91CH2817-5, 448 (1991)

${ }^{4}$ Benjamin W, Chui, and Timothy D. Stowe, Solid-State Sensor and Actuator Workshop (Hilton Head, South Carolina, 1996), p. 219.

${ }^{5}$ T. Gotszalk, R. Linnemann, and I. W. Rangelow, Proc. SPIE 2780, 376 (1996).

${ }^{6}$ J. A. Harley and T. W. Kenny, J. Microelectromech. Syst. 9, 226 (2000).

${ }^{7}$ F. N. Hooge, Phys. Lett. A 29, 139 (1969).

${ }^{8}$ F. N. Hooge and T. G. M. Kleinpenning, Rep. Prog. Phys. 44, 479 (1981).

${ }^{9}$ L. K. J. Vandamme, 7th International Conference on Noise in Physical Systems, Montpellier, Amsterdam, (1983), p. 183.

${ }^{10}$ F. N. Hooge, IEEE Trans. Electron Devices 41, 1926 (1994).

${ }^{11}$ X. Y. Chen, Solid-State Electron. 43, 1715 (1999).

${ }^{12}$ Ren Lona and H. H. Hooge, Phys. Rev. B 176, 209 (1992).

${ }^{13}$ H. de Graaff and M. Huybers, J. Appl. Phys. 54, 2504 (1982).

${ }^{14}$ L. K. J. Vandamme, J. Appl. Phys. 59, 3169 (1986). 